\title{
Modelos de atenção integral para idosos no mundo: revisão da literatura
}

\section{| ${ }^{1}$ Nádia Placideli, 2 Silvia Bocchi |}

Resumo: Revisão integrativa da literatura nacional e internacional sobre modelos de atenção integral para idosos, a partir de seis artigos analisados na íntegra e localizados por meio de buscas sistematizadas, nas bases de dados LILACS, PubMed, Scopus, CINAHL e Web of Science, nos últimos cinco anos. Os resultados demonstram haver modelos inovadores para atenção integral ao idoso, principalmente nos países desenvolvidos, focados nos cuidados de longo prazo aos idosos frágeis; todos eles frisam os diversos desafios para adequação, implementação e manutenção destes modelos que considerem as contínuas demandas desta população. Esta pesquisa aponta a necessidade da construçáo de modelos de atenção integral que contemplem as diversas demandas dos idosos e que sejam integrados com a articulação entre serviços de saúde e sociais, para o avanço da promoção do envelhecimento ativo e na sustentabilidade ao longo do tempo de tais propostas. Isso constitui demanda emergencial para países com acelerado processo de envelhecimento populacional, como é o caso brasileiro.

> Palavras-chave: idoso; atenção à saúde do idoso; serviços de saúde para idosos; integralidade; intersetorialidade.

\author{
1 Faculdade de Medicina, \\ Universidade Estadual \\ Paulista Júlio de Mesquita \\ Filho. Botucatu-SP, Brasil \\ (nadiaplacideli@hotmail.com). \\ ORCID: 0000-0002-8204-0668 \\ ${ }^{2}$ Faculdade de Enfermagem, \\ Universidade Estadual Paulista \\ Júlio de Mesquita Filho. Botucatu- \\ SP, Brasil (silvia.bocchi@unesp.br). \\ ORCID: 0000-0002-2188-009X
}

Recebido em: 07/08/2019 Aprovado em: 03/03/2020 Revisado em: 20/08/2021 


\section{Introdução}

As implicações do envelhecimento populacional são profundas, especialmente relacionadas a formulação de políticas públicas, mudanças nos sistemas de saúde, formação de profissionais e planejamentos orçamentários. Todavia, é um desafio previsível no século em que se espera, pela primeira vez na história, que a maioria das pessoas ultrapasse os sessenta anos. Desta maneira, é necessário introduzir as diretrizes do envelhecimento ativo para todas as políticas e em todos os níveis de governo, tornando o envelhecimento uma oportunidade valiosa às sociedades (OMS, 2015; SCHIDT et al., 2008; LOUVISON et al., 2008; WHO, 2004).

É imprescindível, diante dessa realidade, que os países adotem novos modelos de atenção à população, substituindo os modelos curativistas centrados na doença por àqueles orientados pela atenção integral, direcionados ao monitoramento e manutenção da capacidade funcional dos indivíduos (OMS, 2015; VERAS et al., 2014), estruturados numa perspectiva de integração entre serviços de saúde e sociais para a população de idosos (LOUVISON et al., 2008).

Alguns países têm avançado na implementação de modelos inovadores para atenção integral aos idosos como Canadá, Estados Unidos, Austrália, Holanda, dentre outros, com propostas desenhadas para suprir as demandas dos idosos no território, por meio dos cuidados de longo prazo especialmente para as pessoas idosas frágeis, a partir de programas orientados pelo Integrated Services Delivery (ISD) (VERAS et al., 2014; MANN; DEVINE; MCDERMOTT, 2019; BAXTER et al., 2018).

Tendo em vista o cenário, o Brasil que será o sexto país no mundo com número absoluto de idosos até o final da próxima década (2030) (ILC, 2015; WHO, 2011) necessita repensar a organização, a gestão e a implementação de ações adequadas para atender às demandas dos idosos focadas no alcance do envelhecimento ativo, numa visão prospectiva rompendo com estereótipos e preconceitos relacionados a velhice (DEBERT, 1999; OMS, 2015; VERAS et al., 2014).

Para que possa ser proposto um modelo de atenção integral ao idoso no contexto brasileiro, é importante reconhecer a realidade mundial sobre tal fato. Desta forma, o presente estudo objetivou analisar a produçáo científica mundial que tiveram como objeto de estudo demonstrar a implementação de modelos de atenção integral ao idoso. ${ }^{1}$ 


\section{Métodos}

Realizou-se revisão integrativa da literatura a partir da pergunta norteadora: como se configuram globalmente os modelos de atenção integral ao idoso, assim como suas potencialidades e fragilidades? Este tipo de revisão constitui método de pesquisa para elaboração de síntese de conhecimento produzido por estudos já publicados e possibilita obter conclusóes sobre determinado objeto de estudo ou temática, subsidiando a tomada de decisão nas práticas diárias, além de apontar lacunas no conhecimento que devem ser preenchidas com novas pesquisas (SOUZA; SILVA; CARVALHO, 2010; MENDES; SILVEIRA; GALVÃO, 2008).

A revisão integrativa compreende as seguintes etapas: 1) estabelecimento do problema (definição do tema da revisão em forma de questão ou hipótese primária); 2) seleção da amostra, após definição dos critérios de inclusão; 3) caracterização dos estudos (definem-se as características ou informações a serem coletadas dos estudos, por meio de critérios claros, norteados por instrumento); 4) análise dos resultados (identificando similaridades e conflitos); 5) apresentação e discussão dos achados (SOUZA; SILVA; CARVALHO, 2010; MENDES; SILVEIRA; GALVÃO, 2008).

Ademais, classificaram-se os achados conforme os níveis de evidências científicas variando do nível 1, que caracteriza evidências provenientes de revisôes sistemáticas e metanálise, até o nível 7, evidências oriundas de opinióes de autoridades (MELNYK; FINEOUT-OVERHOLT, 2005).

Realizou-se a busca de artigos, no mês de maio de 2019, indexados nas bases de dados: LILACS (Literatura Latino-Americana em Ciências da Saúde); PubMed; Web of Science; CINAHL (Current Nursing and Allied Health Literature) e Scopus. A escolha destas bases de dados foi definida por incluir material técnico-científico conceituado nas áreas da saúde em contexto nacional e internacional.

Os descritores na língua inglesa utilizados para busca foram: "elderly" OR "aged", "integrated care", "aged care", "primary health care" "delivery of health care, integrated", "public health services", "health services for the aged", "comprehensive health care" $\mathrm{e}$ "organization and administration", para a língua portuguesa os descritores foram "modelo", "rede", "atenção", "integral” e "idoso". Adotaram-se como critérios de inclusão artigos indexados nas bases de dados, no período de $1^{\circ}$ de janeiro de 2015 a 31 de maio de 2019, nos idiomas inglês, português e espanhol, incluindo os de revisão, desde que completos e com resumos, de livre acesso ou por meio das bases de 
dados no Portal de Periódicos da CAPES (www.capes.gov.br), assim como deveriam responder à pergunta norteadora.

Para seleção dos artigos, realizou-se uma primeira análise dos títulos e resumos, sendo então excluídos aqueles que não se relacionavam com o objeto de estudo; seguiu-se com a segunda análise, a partir da leitura na íntegra dos artigos que se aproximaram em responder à pergunta norteadora, o que possibilitou definir a amostra final. Os artigos incluídos na revisão foram classificados conforme os níveis de evidência (MELNYK; FINEOUT-OVERHOLT, 2005), cujo processo de seleção encontra-se sintetizado na figura 1.

Figura 1. Fluxograma de síntese da construçáo da amostra.

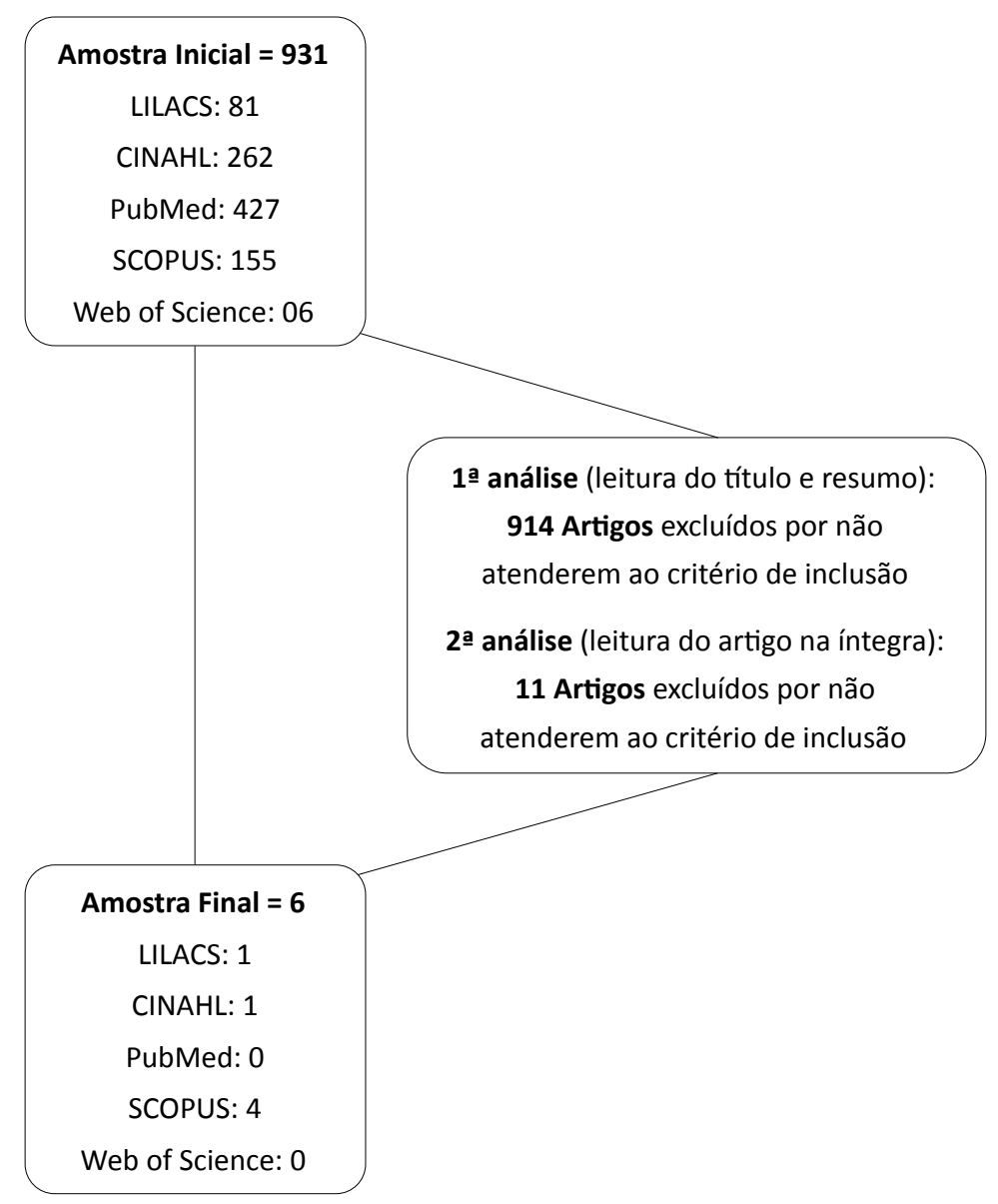

Fonte: elaborado pelas autoras. 


\section{Resultados e Discussão}

A pesquisa nas bases de dados selecionadas, segundo estratégias de busca utilizadas, resultou no total de 931 artigos; após análise exaustiva, foram selecionados seis, os quais mais se aproximaram em responder à pergunta norteadora, contemplando assim o objeto de estudo e os critérios de inclusão preestabelecidos. Ressalta-se que a maioria dos achados apresentavam propostas de modelos ou açóes direcionadas às doenças crônicas não transmissíveis no geral, especialmente quanto ao diabetes mellitus e os cânceres.

Dos artigos inseridos um deles é nacional, estando em idioma português, extraído da base de dados LILACS. Os demais artigos (cinco) são internacionais, todos eles em idioma inglês, sendo dois referentes a estudos realizados na Holanda, e os demais distribuídos igualmente entre Japão, Austrália e Estados Unidos; todos extraídos das bases de dados CINAHL e Scopus.

Com relação à orientação metodológica, quatro artigos classificam-se em abordagem qualitativa e dois em quantitativa; dois no nível de evidência 4 (provenientes de estudos de coorte e caso-controle) e os demais no nível 6 (derivados de um único estudo descritivo ou qualitativo). As informaçôes detalhadas sobre os artigos selecionados podem ser acompanhadas no quadro 1 . 
Quadro 1. Caracterização da amostra de artigos nacionais e internacionais sobre modelos de atenção integral ao idoso, segundo título, autores, ano e periódico publicado, métodos, objetivos, principais resultados e conclusões, indexados nas bases de dados LILACS, CINAHL, SCOPUS, de 1\%/01/2015 a 31/05/2019

\begin{tabular}{|c|c|c|c|c|}
\hline $\begin{array}{c}\text { Artigo/Autores/ } \\
\text { Ano/Título/ } \\
\text { Periódico }\end{array}$ & $\begin{array}{l}\text { Tipo de Estudo/ } \\
\text { Amostra/Local/ } \\
\text { País/Nível de } \\
\text { evidência }\end{array}$ & Objetivo(s) & Principais Resultados & Conclusóes \\
\hline $\begin{array}{l}\text { Artigo 1. } \\
\text { OLIVEIRA, M. } \\
\text { R, VERAS, R. } \\
\text { P, CORDEIRO, } \\
\text { H. A. 2018. A } \\
\text { importância da } \\
\text { porta de entrada } \\
\text { no sistema: o } \\
\text { modelo integral } \\
\text { de cuidado para } \\
\text { o idoso. Physis } \\
\text { Revista de Saúde } \\
\text { Coletiva. }\end{array}$ & $\begin{array}{l}\text { Estudo teórico/ } \\
\text { Rio de Janeiro/ } \\
\text { Brasil/Nível } 6\end{array}$ & $\begin{array}{l}\text { Apresentar um } \\
\text { modelo inovador de } \\
\text { cuidado integral ao } \\
\text { idoso, direcionado } \\
\text { ao setor privado à } \\
\text { saúde, a partir de } \\
\text { duas experiências } \\
\text { brasileiras: o da } \\
\text { UnATI- UERJ e } \\
\text { do Projeto Idoso } \\
\text { Bem-Cuidado (da } \\
\text { Agência Nacional de } \\
\text { Saúde Suplementar) }\end{array}$ & $\begin{array}{l}\text { Identificação de risco e a } \\
\text { integralidade na atenção nos } \\
\text { diversos pontos da rede de } \\
\text { atençáo ao idoso refletem } \\
\text { a proposta inovadora do } \\
\text { modelo construído. }\end{array}$ & $\begin{array}{l}\text { Transformar a } \\
\text { lógica do cuidado } \\
\text { a saúde no Brasil é } \\
\text { um grande desafio, } \\
\text { principalmente } \\
\text { quando se foca na } \\
\text { atenção ao idoso, } \\
\text { contudo tornou-se } \\
\text { uma necessidade } \\
\text { eminente para que } \\
\text { possa ser fornecido } \\
\text { o cuidado integral, } \\
\text { adequado e de } \\
\text { qualidade a estes } \\
\text { indivíduos. A mudança } \\
\text { deve estar pautada } \\
\text { no cotidiano dos } \\
\text { serviços, na formação } \\
\text { dos profissionais de } \\
\text { saúde, na organização } \\
\text { e gestáo do sistema } \\
\text { de saúde e no seu } \\
\text { financiamento. }\end{array}$ \\
\hline $\begin{array}{l}\text { Artigo } 2 . \\
\text { WALKER, } \\
\text { R, JOHNS, J, } \\
\text { HALLIDAY, D. } \\
\text { 2015. How older } \\
\text { people cope with } \\
\text { fraily within } \\
\text { the context of } \\
\text { transition care } \\
\text { in Australia: } \\
\text { implications for } \\
\text { improving service } \\
\text { delivery. Health } \\
\text { and Social Care in } \\
\text { the community }\end{array}$ & $\begin{array}{l}\text { Estudo } \\
\text { qualitativo/ } 20 \\
\text { idosos/ Adelaide, } \\
\text { sul da Austrália/ } \\
\text { Nível } 6\end{array}$ & $\begin{array}{l}\text { Examinar como } \\
\text { as pessoas idosas } \\
\text { inseridas em } \\
\text { um Programa } \\
\text { de Cuidados de } \\
\text { Transição lidam } \\
\text { com a fragilidade } \\
\text { e discutir as } \\
\text { implicaçóes a fim } \\
\text { de melhorar este } \\
\text { modelo de serviços. }\end{array}$ & $\begin{array}{l}\text { Foram identificadas três } \\
\text { categorias principais a } \\
\text { partir das experiências } \\
\text { dos idosos inseridos no } \\
\text { Programa de Cuidados } \\
\text { de Transição: "uma nova } \\
\text { definição de recuperaçáo"; } \\
\text { "complexidades do controle" } \\
\text { e "o desempoderamento do } \\
\text { sistema". }\end{array}$ & $\begin{array}{l}\text { No geral, o estudo } \\
\text { destacou que os } \\
\text { benefícios associados } \\
\text { aos cuidados de } \\
\text { transição podem } \\
\text { ser prejudicados } \\
\text { pela fragmentação } \\
\text { na prestação de } \\
\text { serviços com a não } \\
\text { continuidade do } \\
\text { cuidado e falhas na } \\
\text { comunicação entre } \\
\text { profissionais, idosos e } \\
\text { cuidadores, perda de } \\
\text { controle e incertezas } \\
\text { em torno do suporte } \\
\text { futuro. }\end{array}$ \\
\hline
\end{tabular}

continua... 


\begin{tabular}{|c|c|c|c|c|}
\hline $\begin{array}{c}\text { Artigo/Autores/ } \\
\text { Ano/Título/ } \\
\text { Periódico }\end{array}$ & $\begin{array}{l}\text { Tipo de Estudo/ } \\
\text { Amostra/Local/ } \\
\text { País/Nível de } \\
\text { evidência }\end{array}$ & Objetivo(s) & Principais Resultados & Conclusóes \\
\hline $\begin{array}{l}\text { Artigo } 3 . \\
\text { LETTE, M. et al. } \\
\text { 2015. Initiatives } \\
\text { on early detection } \\
\text { and intervention } \\
\text { to proactively } \\
\text { identify health } \\
\text { and social } \\
\text { problems in } \\
\text { older people: } \\
\text { experiences from } \\
\text { the Netherlands. } \\
\text { BMC Geriatrics. }\end{array}$ & $\begin{array}{l}\text { Estudo } \\
\text { descritivo } \\
\text { qualitativo/ } \\
17 \text { experts } \\
\text { em cuidados } \\
\text { preventivos } \\
\text { para idosos } \\
\text { e } 21 \text { idosos } \\
\text { voluntários } \\
\text { (por meio de } \\
3 \text { entrevistas } \\
\text { em grupo). } \\
\text { Holanda/ } \\
\text { Nível } 6\end{array}$ & \begin{tabular}{|l|} 
Identificar \\
iniciativas de \\
detecçáo precoce \\
e intervenção para \\
pessoas idosas e \\
comparar suas \\
características; \\
explorar as \\
experiências de \\
profissionais com \\
essas iniciativas; \\
e analisar em que \\
medida as iniciativas \\
existentes atendem \\
às preferências e \\
necessidades das \\
pessoas idosas.
\end{tabular} & $\begin{array}{l}\text { Foram identificadas oito } \\
\text { iniciativas de detecçáo } \\
\text { e intervenção precoces } \\
\text { para idosos na Holanda, } \\
\text { inseridas em dois grupos; } \\
\text { o grupo "iniciativas para } \\
\text { detectar idosos frágeis } \\
\text { com risco de deterioração" } \\
\text { foram identificadas açóes } \\
\text { baseada no cenário de } \\
\text { centros de saúde para idosos } \\
\text { e visitas por voluntários; } \\
\text { e no outro grupo para } \\
\text { "detectar problemas de } \\
\text { saúde e bem-estar em idosos } \\
\text { frágeis, a fim de otimizar a } \\
\text { prestação de serviços sociais } \\
\text { e de saúde" foram descritas } \\
\text { iniciativas realizadas por } \\
\text { equipe multiprofissional } \\
\text { da atenção primária, } \\
\text { cuidados hospitalares e } \\
\text { durante a transferência } \\
\text { hospitalar, visita domiciliar } \\
\text { por profissionais de saúde e } \\
\text { social, visitas por voluntários } \\
\text { idosos, abordagem } \\
\text { integrada de vizinhança } \\
\text { com participaçáo de } \\
\text { profissionais da comunidade } \\
\text { e as visitas por munícipes } \\
\text { (conhecidas como conversas } \\
\text { na mesa da cozinha). As } \\
\text { diversas iniciativas possuem } \\
\text { objetivos, público-alvo e } \\
\text { desenvolvimento diferentes. }\end{array}$ & $\begin{array}{l}\text { Embora haja } \\
\text { uma ampla gama } \\
\text { de iniciativas } \\
\text { disponíveis, há uma } \\
\text { discrepância entre } \\
\text { oferta e demanda. } \\
\text { As iniciativas } \\
\text { atuais abordam } \\
\text { insuficientemente } \\
\text { as necessidades das } \\
\text { pessoas idosas frágeis. } \\
\text { O estudo sugeriu uma } \\
\text { desarticulação das } \\
\text { diversas iniciativas de } \\
\text { detecção precoce de } \\
\text { fragilidade em idosos } \\
\text { na Holanda. }\end{array}$ \\
\hline
\end{tabular}

continua... 


\begin{tabular}{|c|c|c|c|c|}
\hline $\begin{array}{c}\text { Artigo/Autores/ } \\
\text { Ano/Título/ } \\
\text { Periódico }\end{array}$ & $\begin{array}{l}\text { Tipo de Estudo/ } \\
\text { Amostra/Local/ } \\
\text { País/Nível de } \\
\text { evidência }\end{array}$ & Objetivo(s) & Principais Resultados & Conclusóes \\
\hline $\begin{array}{l}\text { Artigo } 4 . \\
\text { VESTJENS, } \\
\text { L. et al. } 2018 \text {. } \\
\text { Evaluating } \\
\text { an integrated } \\
\text { primary care } \\
\text { approach to } \\
\text { improve well- } \\
\text { being among } \\
\text { frail community- } \\
\text { living older } \\
\text { people: A theory- } \\
\text { guided study } \\
\text { protocol. BMC } \\
\text { Geriatrics }\end{array}$ & $\begin{array}{l}\text { Estudo caso- } \\
\text { controle/ } 500 \\
\text { idosos ( } 250 \\
\text { idosos grupo } \\
\text { intervenção } \\
\text { e } 250 \text { idosos } \\
\text { grupo controle) } \\
\text { e } 11 \text { médicos } \\
\text { clínicos gerais } \\
\text { do Programa } \\
\text { "Finding and } \\
\text { Folow-up or } \\
\text { Frail older } \\
\text { persons (FFF)" } \\
\text { e } 4 \text { médicos } \\
\text { clínicos gerais } \\
\text { fornecedores } \\
\text { de atenção } \\
\text { usual/ Holanda/ } \\
\text { Nível } 4\end{array}$ & $\begin{array}{l}\text { Descrever um } \\
\text { modelo teórico } \\
\text { para avaliação } \\
\text { de abordagens } \\
\text { integradas da } \\
\text { atenção primária } \\
\text { no olhar aos idosos } \\
\text { frágeis a fim de } \\
\text { compreender } \\
\text { a eficácia e } \\
\text { propor e avaliar } \\
\text { o potencial do } \\
\text { Programa "Finding } \\
\text { and Folow-up } \\
\text { or Frail older } \\
\text { persons (FFF)", } \\
\text { na perspectiva } \\
\text { de avaliação de } \\
\text { efeito, avaliação de } \\
\text { processo e avaliação } \\
\text { econômica. }\end{array}$ & $\begin{array}{l}\text { Proposição para avaliar uma } \\
\text { abordagem de cuidados } \\
\text { integrada complexa, } \\
\text { de multicomponentes, } \\
\text { como FFF, que possibilite } \\
\text { compreender com } \\
\text { rigorosidade o programa. } \\
\text { Com uso de combinação } \\
\text { de métodos quantitativos } \\
\text { e qualitativos avaliando } \\
\text { não apenas a eficácia de } \\
\text { uma abordagem, visando o } \\
\text { bem-estar de idosos frágeis, } \\
\text { mas também processo e o } \\
\text { custo-efetividade. }\end{array}$ & $\begin{array}{l}\text { O estudo de avaliação } \\
\text { proposto é abrangente } \\
\text { com base em um } \\
\text { quadro teórico, a fim } \\
\text { de revelar uma visão } \\
\text { sobre a eficácia (custo) } \\
\text { e os mecanismos } \\
\text { subjacentes da } \\
\text { abordagem pró-ativa } \\
\text { de atençâo primária } \\
\text { integrada focada em } \\
\text { idosos frágeis FFF; em } \\
\text { que o desenho quase- } \\
\text { experimental apresenta } \\
\text { alguns desafios. }\end{array}$ \\
\hline $\begin{array}{l}\text { Artigo 5. } \\
\text { ELGEL, P. A, } \\
\text { et al. 2016. The } \\
\text { Geriatrics in } \\
\text { Primary Care } \\
\text { Demonstration: } \\
\text { Integrating } \\
\text { Comprehensive } \\
\text { Geriatric } \\
\text { Care into the } \\
\text { Medical Home: } \\
\text { Preliminary } \\
\text { Data. Journal } \\
\text { of the American } \\
\text { Geriatrics Society. }\end{array}$ & $\begin{array}{l}\text { Estudo de } \\
\text { coorte / } 50 \\
\text { idosos inscritos } \\
\text { no Programa } \\
\text { "Geriatrics in } \\
\text { Primary Care } \\
\text { (GPC)"/ Boston, } \\
\text { Estados Unidos } \\
\text { da América/ } \\
\text { Nível } 4 .\end{array}$ & $\begin{array}{l}\text { Determinar as } \\
\text { características } \\
\text { clínicas, } \\
\text { necessidades } \\
\text { e padróes de } \\
\text { cuidado dos idosos } \\
\text { encaminhados } \\
\text { ao Programa } \\
\text { “Geriatrics in } \\
\text { Primary Care } \\
\text { (GPC)" e analisar } \\
\text { a efetividade do } \\
\text { Programa GPC } \\
\text { às necessidades de } \\
\text { serviços geriátricos } \\
\text { dentro dos cuidados } \\
\text { primários. }\end{array}$ & $\begin{array}{l}\text { Foi observado que dentre os } \\
\text { idosos inscritos no Programa } \\
\text { GPC e acompanhados no } \\
\text { estudo, após um ano: o } \\
\text { número médio de visitas } \\
\text { para subespecialidade } \\
\text { clínica diminuiu } \\
\text { significativamente, } \\
\text { enquanto o número de } \\
\text { visitas baseadas na atenção } \\
\text { primária permaneceu } \\
\text { estável; o contato telefônico } \\
\text { pelo GPC e a colaboração } \\
\text { com os médicos da atenção } \\
\text { primária substituíram } \\
\text { os cuidados geriátricos } \\
\text { de acompanhamento de } \\
\text { rotina. O GPC facilitou } \\
\text { transiçóes planejadas para } \\
\text { centros de reabilitação, casa } \\
\text { de repouso, unidades de } \\
\text { demência e atendimento } \\
\text { domiciliar. }\end{array}$ & $\begin{array}{l}\text { O GPC fornece } \\
\text { cuidados geriátricos } \\
\text { eficientes e } \\
\text { abrangentes e } \\
\text { gerenciamento de } \\
\text { casos, preservando as } \\
\text { relações estabelecidas } \\
\text { entre os pacientes } \\
\text { e a equipe de } \\
\text { atençáo primária. } \\
\text { Os resultados } \\
\text { preliminares sugerem } \\
\text { "desfragmentação } \\
\text { do cuidado", } \\
\text { como refletido } \\
\text { por uma redução } \\
\text { significativa no uso } \\
\text { da subespecialidade } \\
\text { clínica, simplicidade } \\
\text { e flexibilidade para } \\
\text { implementaçáo do } \\
\text { modelo (Programa } \\
\text { GPC). }\end{array}$ \\
\hline
\end{tabular}




\begin{tabular}{|c|c|c|c|c|}
\hline $\begin{array}{c}\text { Artigo/Autores/ } \\
\text { Ano/Título/ } \\
\text { Periódico }\end{array}$ & $\begin{array}{l}\text { Tipo de Estudo/ } \\
\text { Amostra/Local/ } \\
\text { País/Nível de } \\
\text { evidência }\end{array}$ & Objetivo(s) & Principais Resultados & Conclusóes \\
\hline $\begin{array}{l}\text { Artigo 6. } \\
\text { HAYASHI, M. } \\
\text { 2015. Japan's } \\
\text { long-term } \\
\text { care policy for } \\
\text { older people: } \\
\text { the emergence } \\
\text { of innovative } \\
\text { "mobilization" } \\
\text { initiatives } \\
\text { following the } \\
\text { 2005 reforms. } \\
\text { Journal of Aging } \\
\text { Studies. }\end{array}$ & $\begin{array}{l}\text { Estudo } \\
\text { qualitativo/ } \\
\text { entrevistas com } \\
\text { funcionários- } \\
\text { chave da área de } \\
\text { gerência em } 6 \\
\text { municípios e } 15 \\
\text { organizaçóes do } \\
\text { terceiro setor/ } \\
\text { Japão/Nível } 6\end{array}$ & $\begin{array}{l}\text { Acrescentar } \\
\text { compreensôes atuais } \\
\text { sobre o sistema de } \\
\text { Cuidados de Longo } \\
\text { Prazo para idosos } \\
\text { no Japão, refletindo } \\
\text { as perspectivas } \\
\text { essencialmente de } \\
\text { questóes anteriores } \\
\text { relativamente } \\
\text { negligenciadas, } \\
\text { incluindo o impacto } \\
\text { das reformas } \\
\text { desde } 2005 \text { e, } \\
\text { especialmente, } \\
\text { a introdução } \\
\text { da estratégia de } \\
\text { "mobilização". }\end{array}$ & $\begin{array}{l}\text { Após analisar as } \\
\text { três estratégias de } \\
\text { resposta a mobilização } \\
\text { para a viabilidade e } \\
\text { sustentabilidade do Sistema } \\
\text { de Cuidados de Longo } \\
\text { Prazo para Idosos no Japão: } \\
\text { "o projeto de vizinhança } \\
\text { vigilante”; o projeto de } \\
\text { apoio diário" e "o projeto } \\
\text { de apoio voluntário com } \\
\text { recompensa”, foi possível } \\
\text { demonstrar claramente } \\
\text { que a avaliação existente, } \\
\text { que por sua vez reflete } \\
\text { o otimismo inicial do } \\
\text { governo para a mobilização } \\
\text { de voluntários idosos } \\
\text { para apoiar seus pares } \\
\text { mais idosos e frágeis, é } \\
\text { pretencioso. }\end{array}$ & $\begin{array}{l}\text { Os achados do estudo } \\
\text { traz subsídios para } \\
\text { maior compreensão } \\
\text { e sugere mais cautela } \\
\text { aos formuladores } \\
\text { de políticas que } \\
\text { pretendem promover } \\
\text { Cuidados de Longo } \\
\text { Prazo para Idosos, } \\
\text { tanto no Japão quanto } \\
\text { para outros países que } \\
\text { estão considerando } \\
\text { fazê-lo. Além disso, } \\
\text { mais avaliaçóes são } \\
\text { necessárias para } \\
\text { obter evidências } \\
\text { a fim de apoiar a } \\
\text { viabilidade financeira } \\
\text { e a sustentabilidade de } \\
\text { tais modelos. }\end{array}$ \\
\hline
\end{tabular}

Fonte: elaborado pelas autoras.

Todos os estudos analisados trouxeram reflexóes acerca da demanda emergente em se construir ou avançar numa atenção adequada e de qualidade focada na população de idosos, diante do envelhecimento populacional que traz especificidades de saúde e sociais, especialmente para os idosos mais idosos (de 85 anos ou mais) que residem nas comunidades (OLIVEIRA; VERAS; CORDEIRO, 2018; WALKER; JOHNS; HALLIDAY, 2015; LETTE et al., 2015; VESTJENS et al., 2018; ENGEL et al., 2016; HAYASHI, 2015).

O envelhecimento populacional é um fenômeno dado mundialmente, e os países têm discutido os desafios advindos desse processo coletivo, especialmente os mais populosos. Segundo dados do censo de Hong Kong (China), estima-se que até o ano de 2031 haja 26\% de idosos, o que representará mais de oito milhóes de pessoas com 65 anos ou mais no município, com expectativa de vida que chegará aos 90 anos para as mulheres (CHAN; CAO, 2015). A China ocupará o primeiro lugar com maior número de idosos e o Brasil a sexta posição entre os países do mundo todo, até 2030 (WHO, 2011). 
A fim de responder a essa demanda, os estudos inseridos nesta revisão demonstram, analisam e/ou avaliam modelos de atenção integral para idosos, a partir de programas organizados na perspectiva do cuidado integral e da integralidade da atenção desenvolvida por diferentes serviços. Levantaram questóes críticas para a implementação satisfatória destes modelos, como a fragmentação do cuidado nos sistemas de saúde, a desarticulação entre os serviços de diferentes esferas, desafiando as estruturas, a organização e manutenção ao longo do tempo destes modelos (OLIVEIRA; VERAS; CORDEIRO, 2018; WALKER; JOHNS; HALLIDAY, 2015; LETTE et al., 2015; VESTJENS et al., 2018; ENGEL et al., 2016; HAYASHI, 2015).

Os estudos que compuseram esta pesquisa podem ser caracterizados como programas, alguns mais abrangentes, outros pontuais. Conforme o conceito de "programação" e "modelo de atençáo" dirigido ao campo da saúde, os serviços podem ser estruturados em uma lógica de funcionamento fundamentada em programas operando desta maneira por meio de um "modelo de atenção", compreendido em uma perspectiva ampla, como a organização de serviços por distintos níveis de complexidades tecnológicas de forma a estabelecer redes integradas de atenção a problemas ou a grupos populacionais específicos (MENDES, 2009; 2010; TEIXEIRA; VILASBÔAS, 2014).

Os estudos demonstraram divergências quanto à orientação metodológica para apresentar e/ou avaliar os modelos de atenção integral ao idoso, desde estudos qualitativos conduzidos a partir de entrevistas com idosos, profissionais e informantes-chave até estudos de caso-controle e de coorte. As localidades onde ocorreram os estudos foram em diferentes continentes do planeta, refletindo a importância global desta temática.

O cerne dos modelos propostos também diferiu: alguns apostaram a atenção primária como coordenadora e o ponto inicial destas açôes; outros tomaram o perfil dos idosos para sua estruturação partindo do olhar aos idosos frágeis; e outros confiaram a organização dos programas acerca dos cuidados de transição e de longo prazo (OLIVEIRA; VERAS; CORDEIRO, 2018; WALKER; JOHNS; HALLIDAY, 2015; LETTE et al., 2015; VESTJENS et al., 2018; ENGEL et al., 2016; HAYASHI, 2015).

Ressalta-se que dois estudos (OLIVEIRA; VERAS; CORDEIRO, 2018; HAYASHI, 2015) colocaram a necessidade de planejar e estruturar os modelos 
com foco em atenção integral ao idoso e no cuidado de longo prazo, priorizando a viabilidade e sustentabilidade financeira deles, levantando que ainda sáo poucos os achados no mundo, focados nos custos e manutenção de tais modelos. Neste sentido, especialmente o estudo realizado no Japão em reflexão sobre o sistema de Cuidados de Longo Prazo prioritariamente ofertado à população idosa, desenhado desde os anos 2000, foi salientada a importância de avaliar sua sustentabilidade para suprir a oferta de serviços propostos por esse modelo, para que seja possível acompanhar as demandas da população diante da longevidade e do crescente número de idosos (HAYASHI, 2015).

Neste âmbito, é necessário que as sociedades se reorganizem para lidar com a revolução da longevidade. Uma população envelhecida composta cada vez mais por idosos mais idosos requer não apenas uma readequação de sistemas de serviços, mas também u ma cultura do cuidado entre os cidadãos (KALACHE, 2014).

Diante disto, há diretrizes para a construção de Cidades Amigas dos Idosos, com base nos princípios do envelhecimento ativo (WHO, 2007); alguns países têm avançado no estabelecimento dessas ações, criando novas possibilidades aos idosos para além da oferta por serviços. Na China, há movimentos políticos e implementação de práticas para promoção do envelhecimento ativo à população nos bairros, especialmente com a participação cívica dos idosos, como os programas de cuidados para idosos promovido por outros idosos voluntários que recebem treinamento (CHAN; CAO, 2015).

Neste sentido, o estudo de Lette et al. (2015) procurou evidenciar programas de atenção integral aos idosos na Holanda, por meio de entrevistas com idosos voluntários que auxiliam outros idosos e experts da área. Foram identificadas diferentes iniciativas de deteç̧ão e intervençôes precoces para idosos; compreendidas a partir de dois aspectos: as iniciativas para identificar idosos em risco de fragilização, deterioração, e as destinadas a verificar as necessidades de saúde dos idosos já frágeis, a fim de otimizar a prestação de serviços atuais, tanto de saúde como de assistência social.

$\mathrm{O}$ estudo apontou diferentes iniciativas com o mesmo enfoque que ocorrem de maneira fragmentada, podendo gerar duplicaçóes e divergências na prestação de serviços, sendo necessário superar a desarticulação das ações (LETTE et al., 2015).

Os estudos de Vestjens et al. (2018) e Elgel et al. (2016) se destacam por trazerem propostas avaliativas dos modelos de atenção integral aos idosos recomendados, a fim de demonstrar a efetividade de tais programas e sua possibilidade de implementação. 
A pesquisa de Vestjens et al. (2018) descreve um programa de cuidados primários integrados focado em idosos frágeis, o "Finding and Follow-up of Frail older persons $F F F$ ", o qual tem como elementos essenciais a busca ativa, gestão de caso, avaliação de medicamentos, apoio ao autogerenciamento e o trabalho multidisciplinar. $\mathrm{O}$ objetivo foi traçar um protocolo para avaliação do " $F F F$ " abrangente direcionado por indicadores quantitativos e qualitativos, visando demonstrar o impacto no bem-estar dos idosos acompanhados e o custo-efetividade. Entretanto, os autores reconheceram limitaçôes da proposta, devido à não randomização da amostra e não abordagem junto ao cuidador.

O "Geriatrics in Primary Care - GPC" é complementar ao modelo de equipes de cuidados direcionadas aos idosos nos Estados Unidos, adicionando um médico geriatra e enfermagem geriátrica, diferindo, entretanto, do GRACE (Geriatric Care Management for Low Income Seniors), Program of All-inclusive Care for the Elderly e Guided Care (GC). Tem como características a coordenaçáo e gestão do cuidado a partir da avaliação, planejamento e monitoramento, engajamento da família e paciente e acesso facilitado à equipe; sugerindo ganhos aos idosos, especialmente quanto à preservação de vínculo entre paciente e equipe de atenção primária (ELGEL et al., 2016).

A avaliação é uma das melhores ferramentas para responder e justificar os caminhos tomados por governos para responder ao envelhecimento populacional, ao desenvolvimento tecnológico e à crise financeira pública, além de dar continuidade na garantia ao acesso equitativo, a todos os cidadáos, por serviços de qualidade (BROUSSELLE et al., 2011). É fundamental o reconhecimento das açóes de avaliação como base intrínseca ao planejamento, no suporte à elaboração de políticas, ao processo decisório e de formação dos sujeitos envolvidos, de forma permanente e contínua (CONTANDRIOPOULOS, 2006). Torna-se essencial para demonstrar a efetividade dos modelos de atenção integral para a saúde do idoso e à sua sustentabilidade financeira.

Os diferentes modelos apontam para uma direção única: planejar e implementar atenção de qualidade à população idosa, com vistas a suprir suas demandas ao longo do tempo. Nessa perspectiva, na Inglaterra o sistema de saúde (Nacional Health Service - NHS) vem se organizando para ofertar cuidados adequados para toda a sua população que envelhece, especialmente aos idosos. O NHS ressaltou a importância de reforçar políticas de assistência social e reestruturar seu financiamento para que 
seja possível desempenhar as provisóes de saúde ao longo do tempo a estes indivíduos (AgeUK, 2017). Constatou-se, na Finlândia, um aumento no uso de serviços sociais privados por idosos que poderá repercutir no modelo de organização dos serviços, requerendo uma investigação detalhada (MATHEW; KRÖGER, 2016).

Diante dos resultados e análises levantadas por esses estudos, foi possível destacar as principais potencialidades e fragilidades para o desenvolvimento dos modelos de atenção integral ao idoso no mundo, bem como dos mecanismos para avaliação destes, focadas por alguns, que seguem no quadro 2 .

Quadro 2. Principais potencialidades e fragilidades levantadas na amostra de artigos sobre modelos nacionais e internacionais de atenção integral ao idoso, indexados nas Bases de Dados LILACS, CINAHL, Scopus, de 1\%/01/2015 a 31/05/2019

\begin{tabular}{|c|c|c|}
\hline Artigo/Referência (ano) & Potencialidades & Fragilidades \\
\hline $\begin{array}{l}\text { Artigo 1. OLIVEIRA, } \\
\text { M. R, VERAS, R. P, } \\
\text { CORDEIRO, H. A. } \\
2018 .\end{array}$ & $\begin{array}{l}\text { Modelo de cuidado integral para idosos } \\
\text { composto por cinco níveis de atençáo } \\
\text { (acolhimento; núcleo integrado de } \\
\text { cuidado; ambulatório geriátrico; cuidados } \\
\text { complexos de curta duração; cuidados } \\
\text { de longa duração) com possibilidade de } \\
\text { manter a maioria dos idosos nos níveis } \\
\text { leves de cuidados, demandando menos } \\
\text { custos e mantendo os indivíduos ativos. }\end{array}$ & $\begin{array}{l}\text { A implementação é interdependente } \\
\text { de macro mudanças e inovaçóes } \\
\text { especialmente na gestáo e financiamento } \\
\text { do sistema de saúde e formaçáo de } \\
\text { profissionais de saúde. Necessário } \\
\text { demonstrar a efetividade do modelo para } \\
\text { melhoria da qualidade de vida dos idosos } \\
\text { acompanhados e o impacto no sistema } \\
\text { de saúde. }\end{array}$ \\
\hline $\begin{array}{l}\text { Artigo 2. WALKER, R, } \\
\text { JOHNS, J, HALLIDAY, } \\
\text { D. } 2015 .\end{array}$ & $\begin{array}{l}\text { O programa de atendimento de transição } \\
\text { para idosos foi avaliado como satisfatório } \\
\text { e importante pelos idosos acompanhados, } \\
\text { por lhes trazer ganhos como permanecer } \\
\text { em seus próprios domicílios, recuperar a } \\
\text { independência e não precisar de apoio da } \\
\text { família. }\end{array}$ & $\begin{array}{l}\text { O programa de atendimento de transição } \\
\text { para idosos pode ser enfraquecido pela } \\
\text { fragmentação na prestação de serviços, } \\
\text { interrupção da comunicação entre } \\
\text { prestadores de serviços e clientes, bem } \\
\text { como incertezas sobre suportes futuros. }\end{array}$ \\
\hline $\begin{array}{l}\text { Artigo 3. LETTE. M. et } \\
\text { al. } 2015 .\end{array}$ & $\begin{array}{l}\text { Todos os programas/ iniciativas de } \\
\text { ações para detecção e acompanhamento } \\
\text { de idosos frágeis demonstraram a } \\
\text { importância das visitas domiciliares e } \\
\text { a confiança estabelecida entre idosos e } \\
\text { profissionais. }\end{array}$ & $\begin{array}{l}\text { Os programas/ iniciativas de ações } \\
\text { para detecção e acompanhamento de } \\
\text { idosos frágeis estão organizados sob } \\
\text { várias configuraçóes e foco em diversos } \\
\text { domínios, não deixando claro quais } \\
\text { iniciativas são mais benéficas e para } \\
\text { quê, sendo necessária avaliaçóes para } \\
\text { demonstrar a eficácia. }\end{array}$ \\
\hline
\end{tabular}

continua... 


\begin{tabular}{|c|c|c|}
\hline Artigo/Referência (ano) & Potencialidades & Fragilidades \\
\hline $\begin{array}{l}\text { Artigo 4. VESTJENS, } \\
\text { L. et al. } 2018 \text {. }\end{array}$ & $\begin{array}{l}\text { Proposta de avaliação abrangente ao } \\
\text { programa } F F F \text { baseada em estrutura } \\
\text { teórica norteada por métodos quantitativos } \\
\text { e qualitativos, avaliando não apenas a } \\
\text { eficácia junto ao bem-estar de idosos, } \\
\text { mas também a relação custo-benefício e } \\
\text { processo. }\end{array}$ & $\begin{array}{l}\text { Conforme proposta de avaliação do } \\
\text { programa } F F F \text { o desenho do estudo } \\
\text { impossibilitou cegar profissionais de saúde } \\
\text { e os idosos, dificuldade na disposição de } \\
\text { idosos frágeis ao longo do tempo, não } \\
\text { randomização da amostra e não inclusão } \\
\text { de cuidadores informais. }\end{array}$ \\
\hline $\begin{array}{l}\text { Artigo 5. ELGEL, P. A. } \\
\text { et al. } 2016 .\end{array}$ & $\begin{array}{l}\text { O programa GPC disponibilizou } \\
\text { atendimento geriátrico de qualidade, } \\
\text { amplo com gerenciamento de casos, } \\
\text { preservando relaçóes entre idosos e } \\
\text { equipe de atenção primária e redução } \\
\text { no uso de subespecialidades em um } \\
\text { modelo simplificado e flexível para } \\
\text { implementação. }\end{array}$ & $\begin{array}{l}\text { O programa GPC está organizado com } \\
\text { objetivos e métodos fundamentado } \\
\text { na estrutura dos serviços de atençáo } \\
\text { primária de Boston (Estados Unidos } \\
\text { das Américas), o qual recebeu apoio } \\
\text { institucional contínuo, fatores } \\
\text { contribuintes para implementar o modelo, } \\
\text { bem como determinar seu potencial de } \\
\text { sustentabilidade e disseminaçáo. }\end{array}$ \\
\hline $\begin{array}{l}\text { Artigo 6. HAYASHI, } \\
\text { M. } 2015 .\end{array}$ & $\begin{array}{l}\text { Proposta de avaliação qualitativa do } \\
\text { Sistema de Seguro de Cuidados de Longo } \\
\text { Prazo, após as reformas do sistema (em } \\
\text { 2005) que propuseram três estratégias na } \\
\text { tentativa de torná-lo mais sustentável. }\end{array}$ & $\begin{array}{l}\text { Os critérios de inserção ao programa } \\
\text { inicialmente baseavam-se em ter mais } \\
\text { de } 65 \text { anos de idade e avaliaçáo clínica, } \\
\text { desconsiderando circunstâncias sociais } \\
\text { e financeiras, consequentemente } \\
\text { aumentando a demanda e os custos, } \\
\text { em que as três estratégias propostas são } \\
\text { analisadas como náo suficientes para } \\
\text { contornar as problemáticas para sua } \\
\text { sustentabilidade. }\end{array}$ \\
\hline
\end{tabular}

Fonte: elaborado pelas autoras.

Proporcionar atenção abrangente e de qualidade, que supra as demandas advindas da população envelhecida e cada vez mais longeva, tornou-se o grande desafio para os países, especialmente aqueles que experienciam a inversão na pirâmide etária.

$\mathrm{O}$ aumento de deficiências complexas observadas em indivíduos mais longevos, como é o caso das demências neurodegenerativas, levando a processo de perda da autonomia e dependência, tem sido o cerne de interesse dos formuladores de políticas públicas sobretudo na Europa, na busca por encontrar soluçóes inovadoras para garantir a sustentabilidade dos cuidados de longo prazo, expendendo esforços para retardar a dependência formal por cuidados, melhorando a saúde e o bem-estar dos idosos ou assegurando o suprimento de cuidados formais (EUROHEALTH, 2019).

A partir dos estudos analisados, é possível destacar que os modelos de atenção integral para idosos são fundamentados em prover cuidados adequados a esse 
público requerendo serviços integrados nos diferentes pontos do sistema, inclusive da esfera social, demandando acompanhamento da população a longo prazo por equipe multiprofissional. Diante disto, frisa-se a importância de que profissionais da área saúde estejam providos de conhecimentos acerca da velhice e do processo de envelhecimento e voltados ao trabalho interdisciplinar, para que seja possível avançar na implementação de modelos de atenção à população idosa integrais e intersetoriais (MOTTA; AGUIAR, 2007).

No sentido de prover cuidados integrais e contínuos aos idosos a estratégia mais recomendada, visando monitorar e manter a capacidade funcional dos idosos, postergando ou anulando a dependência, é a atenção primária à saúde que deve estar fortalecida, provida de estrutura adequada, recursos necessários e com gestão a partir de abordagem integrada, demonstrando ser o caminho mais eficiente e equitativo (OMS, 2015).

Embora seja imprescindível a implementação de modelos de atenção integral ao idoso, é importante avançar em investigaçóes sólidas que resultem em propostas quanto à manutençáo desses modelos ao longo do tempo, diante do aumento da demanda devido a longevidade e redução das famílias.

\section{Consideraçóes finais}

A presente revisão da literatura aponta para o desafio de se constituir modelos de atenção integral ao idoso que contemplem a heterogeneidade dessa população, desde os idosos saudáveis até os frágeis, uma vez que é na velhice que encontramos as pessoas mais diferentes entre si e em situaçóes de maior vulnerabilidade, requerendo modelos que considerem as necessidades biopsicossociais desses indivíduos e o iminente desígnio de articulação entre as áreas da saúde e social para uma oferta adequada de serviços assistenciais, preventivos e de promoção ao envelhecimento ativo.

Neste sentido, frisa-se a escassez de estudos sobre essa temática, nos últimos cinco anos, tendo em vista o fato do envelhecimento mundial e suas implicações principalmente na demanda por reestruturação dos sistemas de serviços, sobretudo os de saúde e sociais. E, na compreensão das açôes desenvolvidas aos idosos de forma abrangente, visto que quase a totalidade dos achados restringiram-se aos modelos de programas relacionados com as doenças crônicas não transmissíveis, como diabetes e cânceres. 
Considera-se, por meio desta revisão, que há modelos no mundo de atenção integral aos idosos demonstrando ser efetivos, porém iniciativas concentradas em alguns países desenvolvidos. Um dos estudos analisados é nacional e objetivou traçar um modelo de atenção integral ao idoso direcionado ao sistema de saúde suplementar brasileiro; representa importante contribuição neste contexto, mas é fundamental avançar em propostas que contemplem os sistemas de serviços públicos e privados, tendo em vista que a maior parcela dos idosos no país é dependente do setor público.

Foram utilizados vários descritores na língua inglesa para busca nas bases de dados, o que se justifica pela complexidade do tema, salientando a polissemia de conceitos como "modelo", "atenção integral" e "rede"; manteve-se, contudo, a utilização destes, buscando encontrar estudos abrangentes. Reconhece-se que os critérios de inclusão na língua inglesa e portuguesa, bem como a pergunta norteadora que orientou a seleção dos achados, pode ter desconsiderado outras experiências de modelos instituídos, caracterizando os limites desta pesquisa. Entretanto, o estudo demonstra relevância na contribuição à lacuna no conhecimento sobre a implementação de modelos de atenção integral ao idoso, na direção da reestruturação dos sistemas de serviços que promovam atenção de qualidade aos idosos senescentes e senis, em açôes assistenciais, preventivas e de promoção da saúde, desenhadas para suprir as demandas em longo prazo.

Desta maneira, ressalta-se a necessidade de mais estudos nesta perspectiva, para auxiliar países em desenvolvimento que acompanham um acelerado envelhecimento populacional, como é o caso brasileiro, para que estes possam se fundamentar em propostas norteadoras, a fim de reestruturar seus sistemas de atenção à esta população, a partir de evidências empíricas. ${ }^{2}$

\section{Referências}

AgeUK. Briefing: Health and Care of Older People in England 2017. Disponível em: https:// www.ageuk.org.uk/Documents/EN-GB/For-professionals/Research/The_Health_and_Care_ of_Older_People_in_England_2016.pdf?dtrk=true. Acesso em: $1^{\circ}$ jun. 2019.

BAXTER, $S$. et al. The effects of integrated care: a systematic review of UK and international evidence". BMC Health Services Research, v. 18, n. 1, p. 1-13, 2018.

BROUSSELLE, A. et al. A avaliação no campo da saúde: conceitos e métodos. p 51. In: BROUSSELLE, A. et al. (Orgs.). Avaliação conceitos e métodos. Rio de Janeiro: Fiocruz, 2011. 
CHAN, A. C. M.; CAO, T. Age-Friendly Neighbourhoods as Civic Participation: Implementation of an Active Ageing Policy in Hong Kong. Journal of Social Work Practice, v. 29, n. 1, p. 53-68, 2015.

CENTRO INTERNACIONAL DE LONGEVIDADE BRASIL. Envelhecimento ativo: um marco político em resposta à revolução da longevidade. Centro Internacional de Longevidade Brasil. 1a ed. Rio de Janeiro, 2015.

CONTANDRIOPOULOS, A.-P. Avaliando a institucionalização da avaliação. Ciência \& Saúde Coletiva. Rio de Janeiro, v. 11, n. 3, p. 705-711, 2006.

DEBERT, G. G. A construção e a reconstrução da velhice: família, classe social e etnicidade. In. NERI, A. L., Velhice e sociedade. Campinas: Papirus, 1999.

MORAES, E. N. Atenção à saúde do Idoso: aspectos conceituais. Brasília: OPAS, 2012.

ENGEL, P. A. et al. The Geriatrics in Primary Care Demonstration: Integrating Comprehensive Geriatric Care into the Medical Home: Preliminary Data. Journal of the American Geriatrics Society, v. 64, n. 4, p. 875-879, 2016.

EUROHEALTH. Quarterly of the European Observatory on Health Systems and Policies. Enhancing the sustainability of long-term care, v. 25, n. 4, 2019.

HAYASHI, M. Japan's long-term care policy for older people: The emergence of innovative "mobilisation" initiatives following the 2005 reforms. Journal of Aging Studies, v. 33, p. 11-21, 2015.

KALACHE, A. Respondendo à Revolução da Longevidade. Rev. Ciências \& Saúde Coletiva, v. 19, n. 8, 2014.

LETTE, M. et al. Initiatives on early detection and intervention to proactively identify health and social problems in older people: experiences from the Netherlands. BMC Geriatrics, v.15:143, p. 1-13, 2015.

LOUVISON, M. C. P. et al. Desigualdades no uso e acesso aos serviços de saúde entre idosos do município de São Paulo. Rev Saúde Pública, v. 42, n. 4, p. 733-40, 2008.

MANN, J.; DEVINE, S.; MCDERMOTT, R. Integrated care for community dwelling older Australians. Journal of Integrated Care, v. 27, n. 2, p.173-18, 2019.

PUTHENPARAMBIL, M. J.; KRÖGER, T. Using Private Social Care Services in Finland: Free or Forced Choices for Older People? Journal of Social Service Research, v. 42, n. 2, p. 167179, 2016.

MELNYK, B. M.; FINEOUT-OVERHOLT, E. Making the case for evidence-based practice. In: _-____. Evidence-based practice in nursing \& healthcare. A guide to best practice. Philadelphia: Lippincot Williams \& Wilkins; 2005, p. 3-24. 
MENDES, E. V. As redes de atenção à saúde. Rev. Ciência \& Saúde Coletiva, v. 15, n. 5, p. 2297-305, 2010.

. As redes integradas de atenção à saúde. Belo Horizonte: ESP/MG, 2009. As redes de atenção à saúde. Brasília: OPAS, 2011.

MENDES, K. D.; SILVEIRA, R. C.; GALVÃO, C. M. Revisão integrativa: método de pesquisa para a incorporação de evidências na saúde e na enfermagem. Rev. Texto Contexto Enferm, v. 17, n. 4, p. 758-64, 2008.

MOTTA, L. B.; AGUIAR, A. C. Novas competências profissionais em saúde e o envelhecimento populacional brasileiro: integralidade, interdisciplinaridade e intersetorialidade. Ciência \& Saúde Coletiva, v. 12, n. 2, p. 363-372, 2007.

OLIVEIRA, M. R.; VERAS, R. P.; CORDEIRO, H. A. A importância da porta de entrada no sistema: o modelo integral de cuidado para o idoso. Physis: Revista de Saúde Coletiva, Rio de Janeiro, v. 28, n. 4, e280411, 2018.

ORGANIZAÇÃO MUNDIAL DA SAÚDE. Resumo Relatório Mundial de Envelhecimento e Saúde. Brasília: OMS, 2015.

PINHEIRO, R. Integralidade em saúde. In: PEREIRA, I.B.; LIMA, J. C. F. Dicionário da educação profissional em saúde. Rio de Janeiro, 2008. p 255-262.

SCHMIDT, M. I. et al. Doenças crônicas não transmissíveis no Brasil: carga e desafios atuais. The Lancet, Coleção Saúde no Brasil, 2011, p. 108.

SOUZA, M. T.; SILVA, M.D.; CARVALHO, R. Revisão integrativa: o que é e como fazer. Rev. Einstein, v. 8, n. 1, p. 102-6, 2010.

TEIXEIRA, C.F.; VILASBÔAS, A. L. Q. Modelos de atenção à saúde no SUS: transformação, mudança ou conservação? In: PAIM, J. S.; FILHO-ALMEIDA, N. Saúde coletiva: teoria e prática. Rio de Janeiro: Medbook, 2014, p. 237-301.

VERAS, R. P. et al. Integração e continuidade do cuidado em modelos de rede de atenção à saúde para idosos frágeis. Rev. Saúde Pública, v. 48, n. 2, p. 357-365, 2014.

VESTJENS, L; CRAMM, JM; BIRNIE, E; NIEBOER, AP. Evaluating an integrated primary care approach to improve well-being among frail community-living older people: A theoryguided study protocol. BMC Geriatrics, v. 18, n. 1, p. 1-17, 2018.

WALKER, R.; JOHNS, J.; HALLIDAY, D. How older people cope with frailty within the context of transition care in Australia: Implications for improving service delivery. Health and Social Care in the Community, v. 23, n. 2, p. 216-224, 2015.

WORLD HEALTH ORGANIZATION. Active Aging: Towards Age-Friendly Primary Health Care.France,2004.Disponívelem:http://apps.who.int/iris/bitstream/10665/43030/1/9241592184. pdf. Acesso em: 1 jun. 2019. 
. Global friendly cities: a guide. Ageing and Life Course Family and Community Health. Geneva: WHO, 2007. Disponível em: https:/www.who.int/ageing/publications/Global_age_ friendly_cities_Guide_English.pdf. Acesso em: 1 jun. 2019.

. Global Health and Aging. National Institute on Aging. Washington, DC: National Institutes of Health, 2011. Disponível em: https:/www.who.int/ageing/publications/global_ health.pdf?ua=1. Acesso em: 01 de junho de 2019.

\section{Notas}

${ }^{1}$ Compreende-se por Modelo de Atenção Integral ao Idoso o planejamento e implementação de ações e/ ou programas direcionados a essa população, com base nos aspectos biopsicossociais do indivíduo em um olhar holístico e, que aconteça de forma integrada, articulada e horizontalizada com os diversos serviços preventivos e curativos, individuais e coletivos existentes (MORAES, 2012; MENDES, 2011; PINHEIRO, 2008)

${ }^{2}$ N. Placideli: construção do objeto de estudo, discussão teórica do manuscrito, revisão e aprovação da versão final. S. Bocchi: discussão teórica do manuscrito, revisão e aprovação da versão final. 


\section{Abstract}

\section{Comprehensive care models for the elderly in} the world: literature review

Integrative review of national and international literature on models of comprehensive care for the elderly, from six articles analyzed in full and located through systematic searches, in the Lilacs, PubMed, Scopus, CINAHL and Web of Science databases, in the last five years. The results show that there are innovative models for comprehensive care for the elderly, especially in developed countries, focused on long-term care for the frail elderly; all of them emphasize the various challenges for adapting, implementing, and maintaining these models that consider the continuous demands of this population. This research points to the need to build models of comprehensive care that address the several demands of the elderly, integrated with the articulation between health and social services, to advance the promotion of active aging and sustainability over time such proposals. It constitutes an emergency demand for countries with accelerated population aging process, as it is the case in Brazil.

> Keywords: elderly; health care for the elderly; health services for the aged; integrality; intersectoriality. 